\title{
Reconfigured Medication:
}

\author{
Writing Medicine in a
}

\section{Sociotechnical Practice ${ }^{1}$}

\author{
Finn Olesen
}

Randi Markussen

Aarhus University, Denmark

Put in general terms, we aim to show in this paper that it is complicated to simplify a sociotechnical practice. Humans, things, symbolic exchanges, and spatiotemporal coordinations have to be reconfigured in numerous ways before the simplifying procedure appears to be the cause of a new kind of stability. Hence, stability is the result of dynamic processes, and it depends on the participating actors how (well) the simplifying procedure is actualized and for how long it remains stable. Accordingly, simplification is not seen as the cause of a better practice; rather, it is an effect of numerous transformations of existing and new procedures and activities. ${ }^{2}$

The reason we often see simplification as a desirable goal has to do with certain culturally inherited knowledge ideals, whereby Euclid's geometrical economy and Descartes's algebraic representations (among other examples) stand out as ideal models of how to improve our understanding of the world. In science, for instance, the simpler hypothesis will be preferred to the complex

1. This is an enlarged and revised version of a paper in Danish: Randi Markussen and Finn Olesen, "Rekonfigureret medicin: Medicinskrivning i en socioteknisk praksis," in Cyberkulturer og rekonfigurationer, ed. Mette Bryld and Randi Markussen (Copenhagen: Samfundslitteratur, 2003).

2. Similar arguments have been forwarded in Marc Berg, Rationalizing Medical Practice (Cambridge, Mass.: MIT Press, 1997); and in Marc Berg and Stefan Timmermans, "Orders and Their Others: On the Constitution of Universalities in Medical Work," Configurations 8 (2000): 31-61. 
when guided by this ideal. ${ }^{3}$ But simplicity is primarily that: a metaphysical ideal stemming from abstract, a priori categories; and proponents of the ideal of simplicity may easily make the mistake of thinking that abstract categories can be gracefully applied in practical life settings. ${ }^{4}$ Mathematical demonstrative power is generally ill-suited to depicting the heterogeneous relations and processes of non-ideal life situations.

While mathematics is concerned with detached universals, we will argue for the advantage of studying situated particularitiesthat is, the materially located settings in which simplifications are tried out, and where reconfigurations happen in practice. We support this stand through an account of some empirical findings we gathered in the fall of 2000 in a plastic surgery ward at a large Danish hospital. Through a number of visits we studied the successful incorporation of an electronic medication module (EMM) into daily work routines on the ward. Our field study was centered on how medicine, staff, and writing were translated and transformed in order for the EMM to become a stable part of the ward's work routines. ${ }^{5}$ The module is part of an electronic patient record already used by various professionals, both individuals and groups, in the ward. From the start its purpose has been to simplify a number of basic procedures related to medication. By applying the EMM, it is only the doctor who is allowed to write down the prescribed medicine. Before, a specific medication for a patient might be copied onto four or five forms and charts by various health professionals, entailing a persistent risk of faulty reading and misadministering. ${ }^{6}$

3. The philosopher Nelson Goodman has made a classical argument within philosophy of science that simplicity, and not strength or safety, yields the basic logical reasons to prefer one hypothesis to another in scientific thinking: see Nelson Goodman, "Safety, Strength, Simplicity," Philosophy of Science 28 (1961): 150-151.

4. This point has been made by the philosopher of science Rom Harré, in The Philosophies of Science: An Introductory Survey (Oxford: Oxford Paperbacks, 1984). Another philosopher of science, Hilary Putnam, has argued in "Reductionism and the Nature of Psychology," in Mind Design: Philosophy, Psychology, Artificial Intelligence, ed. John Haugeland (Cambridge, Mass.: MIT Press, 1981), pp. 205-219, that although it may be possible to reduce a phenomenon to a microphysical level of description, that will usually be irrelevant to the initial quest for an explanation, since explanatory interests outside of physics usually arise at the level, simple or complex, where the phenomenon is first met and questioned.

5. Markussen and Olesen, "Rekonfigureret medicin" (above, n. 1); Randi Markussen and Finn Olesen, How to Place Material Things: From Essentialism to Material-Semiotic Analysis of Sociotechnical Practice, working paper from "Cyborgs and Cyberspace" (Odense, 2003).

6. For the issue of medication errors, see, for example, Charles Vincent et al., "Adverse Events in British Hospitals-Preliminary Retrospective Record Review," British Medical 
There are two related objectives of this paper. First of all, we wish to encourage a culturally grounded approach to studying the implementation of advanced technology in a community of interacting professionals. By stressing the term "culture" we mean to say that our approach is committed to the material and symbolic doings of actors in everyday life settings. Hence, to us, culture is what people and things do, including the symbolic meanings attached to those actions by the practitioners. In what follows we want to demonstrate that the successful incorporation of the EMM in the hospital ward can be seen as an effect of numerous visible and invisible work processes entailing many reconfigurations of humans, things, and meanings.

The approach is partly inspired by anthropological studies such as those by Lucy Suchman, Julian Orr, and Diana Forsythe, who have all done ethnographic field work to learn how professionals like copy-machine technicians, or artificial intelligence researchers, deal with machines in concrete work situations. ${ }^{7}$ Closely related to this approach is the suggestion from the sociologist and founder of symbolic interactionism Anselm Strauss that one should study articulation work. One of his former students, Susan Leigh Star, has defined this: "Articulation work is work that gets things back 'on track' in the face of the unexpected, and modifies action to accommodate unanticipated contingencies. The important thing about articulation work is that it is invisible to rationalized models of work." ${ }^{8}$ The quotation stresses the importance of getting behind verbal reconstructions

Journal 322 (2001): 517-519; K. W. Ridge et al., "Medication Errors during Hospital Drug Rounds," Qualitative Health Care 4 (1995): 240-243; Jens-Ulrik Rosholm et al., "Polypharmacy and the Risk of Drug-Drug Interaction among Danish Elderly," Danish Medical Bulletin 45 (1998): 210-213. For general information on the issue of electronic medical records see, e.g., the homepage of the Medical Record Institute: http://www.medrecinst.com.

7. Lucy Suchman, Plans and Situated Actions (Cambridge: Cambridge University Press, 1987); Diana Forsythe, "The Construction of Work in Artificial Intelligence," Science, Technology, and Human Values 18:4 (1993): 460-479; Julian Orr, Talking about Machines: An Ethnography of a Modern Job (Ithaca, N.Y.: Cornell University Press, 1996).

8. Susan Leigh Star, "The Sociology of the Invisible: The Primacy of Work in the Writings of Anselm Strauss," in Social Organization and Social Process: Essays in Honor of Anselm Strauss, ed. Anselm Strauss and David R. Maines (New York: de Gruyter, 1991). See also Joan Fujimura, "Constructing 'Do-able' Problems in Cancer-Research: Articulating Alignment," Social Studies of Science 17 (1987): 257-293; Geoffrey Bowker and Susan Leigh Star, Sorting Things Out: Classification and Its Consequences, Inside Technology (Cambridge, Mass.: MIT Press, 1999); Kjeld Schmidt and Liam Bannon, "Taking CSCW Seriously: Supporting Articulation Work," Computer Supported Cooperative Work 1 (1992): 7-40. 
of what has been done in order for a new sociotechnical system to be implemented, or incorporated into daily work practices. One should expect practitioners to perform recurrent, "invisible" work to compensate for the experienced shortcomings of new, and still not contextualized, design. Examples of such work will be narrated in later sections.

Our second objective is to show why it is reductive to motivate the introduction of a new sociotechnical system by pointing to its successful use in other sociotechnical arrangements, or by claiming that the system carries certain inherent qualities that warrant a particular outcome. We suggest, rather, that the successful simplification of work processes may be seen as the effect of multiple undertakings, performed within a gradually expanded chain of situated, partially connected processes..$^{9}$ Both actors and processes will undergo some alterations due to the work. Our observations show that there is a price to be paid for the new simplification, in terms of what the American historian and feminist scholar Donna Haraway characterizes as "transformed materialsemiotic coordinations." 10

Haraway, together with the French sociologist Bruno Latour and other STS scholars, has demonstrated the merits of trying to dissolve absolute ontological boundaries between material and symbolic dimensions of sociotechnical practices. She has identified figures and figurations as explicit expressions of "the tropic quality of all material-semiotic processes, especially in technoscience." 11 By that she wishes to point out that a figuration is not just a figurative beautification of literal speech, nor are pictural utterances "just" images or symbolic expressions of literal meaning; rather, we live with and through such figurations. Figurations are performative images that one may dwell in. The famous cyborg-figure is arguably a special sign of a sociotechnical culture's transgression of any subject/object dichotomy, of any fixed material/mental boundary-work—but there are many other such figurations, Haraway insists. ${ }^{12}$ One may thus choose to study

9. See Marilyn Strathern, Partial Connections (Savage, Md.: Rowman and Littlefield, 1991), for a detailed unfolding of the concept of partial connection.

10. See Donna Haraway, Modest_Witness@Second_Millennium.FemaleMan@_Meets _OncoMouse ${ }^{T M}$ : Feminism and Technoscience (New York: Routledge, 1997).

11. Ibid., p. 11.

12. See Randi Markussen, Nina Lykke, and Finn Olesen, "Interview with Donna Haraway," in Chasing Technoscience: Matrix for Materiality, ed. Don Ihde and Evan Selinger (Bloomington: Indiana University Press, 2003), pp. 47-57. 
things as if they are somehow pregiven objects with certain known properties, or as if they are dynamic elements in a continuous flow of activities. We will follow the latter route and investigate the relationship between things we (can) say about material things, and the stance from which we are able to say such things. To understand this reflexive argument it is necessary to investigate, and possibly subvert, certain modern images of social interaction and materiality. An obvious place at which to begin this task is the concept of technology.

\section{Translating New Technology}

In modernist terminology, new technological systems are often placed in abstract, purified categories. They may be simply classified as "new technology," for example, when a technical system is taken as a means to make a practical domain more efficient. In contrast to such ideas, we claim that "new technology" in practice is an effect of a chain of complicated, dynamic processes that happen in various places and ways. "New technology" is what is left when sociotechnical processes of delegating responsibility have ceased, to use the words of Bruno Latour. ${ }^{13}$

These years there is a struggle in Denmark between various players for the right to define the content of the electronic patient record (EPR). The National Board of Health, politicians, computer companies, several counties, and individual hospitals and wards appear to have overlapping but different ideas about what is required for something to be an EPR. ${ }^{14}$ On a political level, the Danish Ministry for the Interior and Health has published an influential draft of a National IT Strategy for the Health Sector, 2003-2007, the introduction to which reads: "The EPR and clinical-quality databases will effectively underpin a systematic quality growth in the services offered by the health-care sector. At the same time, the EPR will directly bring about improved quality, e.g., fewer medication errors, and it can also provide better information on service and quality to the patient." 15 To us, the excerpt is a good demonstration of both the political commitments to establish (inter)national standards for EPR systems in Denmark, and the underlying modernist anticipation that new technology will improve health-care work. Other players

13. Bruno Latour, Science in Action (Cambridge, Mass.: Harvard University Press, 1987). 14. See EPJ-observatoriets status reports, e.g., 2002.

15. National IT-strategi for sundhedsvoesenet 2003-2007: Draft, Indenrigs- og Sundhedsministeriet (2002), p. 4 (our translation, RM/FO). 
have dissimilar interests and anticipations. In effect, the struggle is over what should count as rational and effective modeling of situated tasks and problems, what is technology, and who has the right to define the terms.

To make this basic observation operational we suggest two models of technology, adapted and molded from Latour's proposals for a sociological understanding of power associations. ${ }^{16}$ The first model encompasses a view of technology to which we object, and the second underpins our own position. Hence, we propose Latour's concepts of diffusion and translation as ideal models to understand the dissemination of technical systems in society. To exemplify this, let us follow the circulation of prescribed medications in a hospital ward.

In the diffusion model, a doctor prescribes a drug in a specific dose and form to a patient, and the prescription will-ideallybe sent to the latter. The "only" task of secretaries, pharmacists, nurses, assistant nurses, and others is to mediate the prescribed drug between doctor and patient. Hence, they function as social agents who are more or less helpful to the doctor's original plan. To ensure the mediation they may use prescription forms, dictaphones, pens, plastic cups, telephones, medicine cupboards, adhesive labels, syringes, and so forth. If errors happen, it is necessary to investigate why and how social agents slowed down, or obstructed, the transmission of medicine from the doctor to the patient-that is, which person erred, and what tool failed? This model makes it possible to speak about three moments in the circulation: (1) it is the original power, that is, the expertise and authority of the doctor, that initiates the circulation of the drug; (2) this power is turned into a kind of inertia, which is conserved during the entire transmission; and (3) the social mediators' work may slow down or speed up the completed circulation. ${ }^{17}$ If we look out for these moments, it will be evident that there are rational human subjects, material objects, and a mediating, social world, and consequently a number of a priori dichotomies to count on. The quotation from the Danish Ministry for the Interior and Health indicates a perfect agreement with this line of thinking.

In the translation model, on the other hand, it is assumed that all participants, all agents-both humans and nonhumans-re-

16. Bruno Latour, "The Powers of Association" in Power, Action and Belief, ed. John Law (London: Routledge and Kegan Paul, 1986), pp. 264-280; Latour, Science in Action (above, n. 13).

17. See Latour, "Powers of Association" (above, n. 16). 
ceive and translate the prescription in accordance with their own projects and interests. ${ }^{18}$ What they dispatch to the next link in the chain of medication is no longer "the same" as that which they received-that is, there is no simple transmission going on. The fate of the prescription is always in the hands of later users, since every link will translate and transform what they receive to make it fit with their own plans and projects. One is reminded of the Italian aphorism "Traduttore, traditore": the one who translates is a traitor (to the original text). But you can do nothing but translate if the text is to be passed on! In the process of translating medicine and passing it on, people become enrolled in the sociotechnical network of transmission; they are also changed in the innovative process. Hence, facts, artifacts, and people must be studied concurrently. "We are never confronted with science, technology, and society, but with a gamut of weaker and stronger associations; thus understanding what facts and machines are is the same task as understanding who the people are," as Latour states in Science in Action. ${ }^{19}$

Below we will try to demonstrate how the translation model is suitable to describe processes of sociotechnical change in the health services. One should not, however, conceive the model in an ontological or psychological sense, expressing the intentions of rational, strategically thinking subjects. Rather, it is intended as a reminder that there is less static rationality and more dynamic agencies in the world than appear in the diffusion model of technological circulation. ${ }^{20}$

18. Bruno Latour, in The Pasteurization of France (Cambridge, Mass.: Harvard University Press, 1988), explains how "translation" has been developed as a technical term during the 1980 s by himself and other STS students "in order to fuse the notions of interest and research program in a more subtle way" (p. 253n16). He then points out three distinct dimensions of the term: First, translation means drift, betrayal, and ambiguity; a translation thus begins from inequivalences between language games, and aims at making equivalency between two propositions. Second, translation defines, in a strategic sense, an obligatory passage point, which furthers the interests of the translator. Finally, the term has a linguistic meaning, so that one version of the language games translates all other language games, and replaces them with the "real meaning" of the issue at hand.

19. Latour, Science in Action (above, n. 13), pp. 140-141.

20. The controversies between rationalists and pragmatists over conceptions of action, information, and cognition have always played a crucial role in the understandings of self and subject domain within the research tradition of information studies. See, for instance, Suchman, Plans and Situated Actions (above, n. 7); Terry Winograd and Fernando Flores, Understanding Computers and Cognition (Norwood, N.J.: Ablex, 1986); Donald Schon, Educating the Reflective Practitioner (Oxford: Jossey-Bass, 1991); Hubert 


\section{Writing}

What is writing, in our understanding? It is necessary to be rather detailed in order to give an idea of the involved microprocesses, which in effect transgress paper, databases, pens, keyboards, graphic interfaces, and words. Writing at the ward is not a neutral, instrumental skill; on the contrary, it is part of a constant microsocial stabilizing of numerous sociotechnical relations, as will be evident.

Historically, writing has always been a powerful means of social control and a principle of organization. ${ }^{21}$ This is also true in our own time, in which communication has become a cultural beacon carried forward by the effects of Internet use and other social interactions involving microprocessors. Also historically speaking, one can point out a strong idealist tradition in Western cultures to separate language from its material contexts and machines, whether those be slate pencils, a printing press, or some other tool for printing: materiality represents simple work, while thoughts and language represent our privileged human form as animal rationale. ${ }^{22}$ Seen in this light, we have inherited a somewhat contradictory relationship with writing. At a modern hitech hospital, writing and reading are extremely important aspects of ensuring the material-semiotic stability in daily work routines. Here one also finds the ambigous relationship to writing where, on the one hand, materialized textuality and documentation (e.g., test results, measurement values, codes) are sine qua nons, but where, on the other hand, many agents aim at a paper-free reorganization of work processes supported by the computer, sometimes denoted the universal machine due to its formal properties. ${ }^{23}$

Dreyfus, What Computers Still Can't Do: A Critique of Artificial Reason (Cambridge, Mass.: MIT Press, 1992); Pelle Ehn, Work-Oriented Design of Computer Artifacts (Stockholm: Arbetslivscentrum, 1988); Donald Norman, The Design of Everyday Things (New York: Doubleday, 1990).

21. See Walter Ong, Orality and Literacy (London: Routledge, 1982); Michael Heim, Electric Language: A Philosophical Study of Word Processing (New Haven, Conn.: Yale University Press, 1987); Henri-Jean Martin, The History and Power of Writing (Chicago: University of Chicago Press, 1988)

22. See Jeffrey Masten et al., eds., Language Machines: Technologies of Literary and Cultural Production (London: Routledge, 1997).

23. According to the logician Alan Turing's momentous description of such machinery, in "On Computable Numbers, with an Application to the Entscheidungsproblem," Proceedings of the London Mathematical Society 42 (1936-37): 230-265. For a popular, and still lucid, description of the machine, see Joseph Weisenbaum, Computer Power and Hu- 
Before October 2, 2000, the doctors on Ward Z of Odense University Hospital prescribed medicine through a dictaphone, and typists wrote the prescription into the electronic patient record; for example, "Rp T Cipramil $10 \mathrm{mg} \times 2$ daily." The transcription was done on first floor of the tower-block hospital, and the resulting prescription text was sent to the tenth floor to the patient unit, either on a loose sheet of paper for the physical version of the journal, or as electronic text. On the tenth floor the nurses read either from one of the two available computer screens, or from the physical prescription sheet, what drugs the particular patient needed to have, and in which dose.

The nurses would copy the prescriptions for the patients assigned to them with a ballpoint pen ${ }^{24}$ onto the medication form, to be inserted in the cardex, which is the nurses' version of a patient record. They also wrote down these details on a small label to be placed at the bottom of the medicine tray, and on a control form to be attached to the wall in the medicine room. Often they would also write on yet another sheet of paper, the nurse's report, which would be placed in the cardex after duty. All in all, the nurses and other staff had to copy the prescriptions onto paper to be put in four or five places, and they often felt uncertain whether the right medicine was being administered to the right patient in the right dose in the right form at the right time.

In the early months of 2000 four nurses and a doctor, making up the prescription group on the ward, decided to implement the EMM starting on October 2. It should be noted that before this date, the nurses clearly had the right to write down medicine as an

man Reason (San Francisco: Freeman, 1976). Basic to Turing's abstract mathematical theory of a universal symbol machine are a thesis and a proof. The thesis states that any effective procedure-that is, any procedure that can be separated into atomic elements and steps-can be expressed in a finite, formal language in a machine matrix; if that proves to be the case, there will exist, for any deterministic system, a functionally equivalent machine (now addressed as a Turing machine). Turing's proof says that there will be a class of universal machines, each of which is able to imitate any other such machine-step by step. Consequently, anything that can be formulated in language, or can be treated logically, can be processed in a Turing machine. Hence, the term "universal machine" for a machinery that has proved so influential on subsequent sociotechnical action and reasoning.

24. The ink of the pen was significant in itself, for the color signals the shift on which the text was written: during the day shift, the nurses would use blue or black ink; in the evening they would use green ink; and the night-shift nurses would use red. This material manifestation of daily rhythms appears to be a widespread convention, as we have learned from comments by nurses and health professionals in other parts of the world. 
integrated part of their work. Seen from the outside, they gave away this right as they began to incorporate the EMM in their work; while the doctors, who did little writing apart from making notes for their own use, took over a right that they had never asked for.

In the new system, it was the doctor doing the prescribing who had to write down the prescription in the EMM. At the same time, the nurses were to refrain from copying medicine, and instead to use the doctor's prescription on printed lists as the basis for their drug administering. Furthermore, the material-semiotic writing space had altered:25 writing medicine was no longer about a nurse using a ballpoint pen or a pencil to write down the name, dose, and so forth of a drug on a piece of paper; instead, it was about a medical doctor using a computer keyboard to type into a module in the electronic patient record what drugs were prescribed for a particular patient. Based on the diffusion model of technological dissemination, one might be tempted to say that the hand and mouth of the doctor have been harmonized in an input activity, while the nurses and other professional groups have been aligned to mediate the output to the patient. But it is far more complicated to write down and print out medicine than can be expressed in a diffusion model: it involves a number of complex coordinations and displacements of existing competencies and agencies, which defy the outcome of this model.

As part of the introduction of the EMM the prescription group constructed a work manual on how to "write" prescriptions and how to "print out" such documents. The terminology and phrases in the manual were based on the original manual supplied by the producers of the software (named "Medicare"). We will call these instructions recipes, to link them to the use of a cookbook: Here one finds the whole spectrum of users, from the very economical food producer who strictly obeys each instruction in the recipe, to the impressionist bon vivant who will be inspired by anything from the title of the recipe to the accompanying picture, to the self-reliant cook who refrains from any use of recipes. Here one also finds the still-missing transitions from the basically semiotic texture of the recipe to the dense, sensual materiality of the prepared meal. The translation from a recipe to a meal depends on numerous situated circumstances and poten-

25. Haraway, Modest_Witness (above, n. 10); Nina Lykke, Randi Markussen, and Finn Olesen, “'There Are Always More Things Going on Than You Thought!': Methodologies as Thinking Technologies. Interview with Donna Haraway, part two," Kvinder, køn og forskning 9:4 (2000): 52-60. 
tials, including the season, skills, economy, needs, tools, place, and raw materials. Who decides if the recipe has been followed, and when is it important? The same goes for the software manual: its fate is in the hands of later users.

Copies of the work manual were placed next to the two computers in the ward's office on the tenth floor, to prevent the writing doctors and the printing nurses from feeling at a loss from day one. The manual contains four recipes, but here we will analyze only two of them, regarding the EMM's most common input and output functions. As we stated in the introduction, it becomes evident how many different actors and processes are "hidden" behind the simple straightforward points in the manual when we begin to unravel the recipes, word by word, line by line. Throughout the inquiry we will attempt to tease out how "banal" knowledge rests on basic handling as its forgotten past. Hence, that which may be taken for granted by computer literates is the outcome of socially embedded learning processes. The actual economy of a design very much depends on the site of application, including the actors and their capabilities to translate the new system into a doable practice. ${ }^{26}$

\section{The EMM in Operation}

\section{Writing Prescriptions}

The first recipe is for the writing down of the prescription. Figure 1 is a close reproduction of its words and design. The reader should imagine the text on the surface of a sheet of white ordinary (A4) paper. Several things can be noted about the involved writing process. First, a high degree of familiarity with the workings of an electronic patient record is presumed. To "open the record" clearly presupposes a familiarity with the vocabulary of electronic archives, since the word "record" is devoid of the materiality (or form) of the physical patient record. Furthermore, the command "open $\mathrm{x}$ " is a very complex order in relation to computing: it may be necessary to switch on the current on the back of the CPU, on the screen, or on the wall; to "insert a disk"

26. Regarding "doable practice," see Fujimura, "Constructing 'Do-able' Problems" (above, n. 8). At our own department we are in the process of upgrading our Macintosh computers to OS X. Among other things, this means changing to a Linux-based systems architecture. Most of the colleagues with whom we have spoken about the change report that part of their everyday knowledge of computers broke down during this transition, because the basic working logic of Linux was unfamiliar to them. Even computer literates may experience the sensation of not having the necessary understanding of "banal" procedures. 


\section{Medicine prescription}

1. Open the record

2. Press Ctrl+3

3. Key in the whole name of the drug, or part of it (e.g., diu or diural)

4. Press Enter

5. Mark the wanted drug in the wanted dose

6. Press Enter

7. Key in the desired dosage, e.g., $1+1+1+0$; or, in the case of i.v. medicine, $0+0+240 \mathrm{mg}+0$, and note down "administer as i.v."

8. Press Tab

9. Choose/write the desired indication

10. Press Tab

11. Choose periodicity

12. Press F8 = Save

Figure 1. The instructions for doctors on how to enter the prescription into the EMM.

or "CD-ROM"; to "point at" some "icon" to "go to" the "page," where you are asked to "key in the PASSWORD"; to "connect to the server"; to "find" the right "field" in the record; to be "denied access"; to "restart the computer," and so forth.

"Press Ctrl+3" is also a complex code. One will fairly soon learn that "Ctrl" signifies a key at the bottom of the keyboard to the left-the string of letters is printed on top of that key. But then you need to know that you are not supposed to press down the key "+" even though it says so! Rather, it is a code telling that you must also press the " 3 " key. Furthermore, one needs to know that the writing instruction "Press Ctrl +3 " has to be executed in a different manner from writing a text sequence, even though the keyboard is more or less identical with the typewriter's qwerty-keyboard: ${ }^{27}$ while the letters in a word are written as a se-

27. The name is derived from the first six letter keys on a typewriter or computer keyboard, when seen from the upper left corner. The position of letters and numbers on the qwerty keyboard has set the standard since the printer Christopher L. Shole developed and sold the original version of this keyboard to the arms manufacturer E. Remington \& Son in 1873: see Robert Pool, Beyond Engineering: How Society Shapes Technology (Oxford: Oxford University Press, 1997), chap. 5; Lisa Gitelman, Scripts, Grooves, and Writing Machines: Representing Technology in the Edison Era (Stanford: Stanford University Press, 1999), chap. 1. History has it that the relative positions of the letters were assigned in a deliberate attempt to slow typists down, since the typebars on the prototype typewriters easily got entangled when the typist wrote quickly. Remington modi- 
quential string, one has to keep the pressure on the "Ctrl" key while pressing once on the " 3 " key. One even has to know that other things result from pressing down keys on a computer than on an ordinary typewriter. On an older, mechanical typewriter the finger may keep a constant pressure on a key without any consequences for the writing process-but the same pressure on the computer key may cause a whole row of " 3 "s, or perhaps the computer will produce a repetitious beep to tell that IT IS REGISTERED that the user wishes to press the " 3 " key!

To get rightly through the second point in the recipe, then, one needs to know about the relatively unique function of the "Ctrl" key. Furthermore, one needs to have achieved certain tactile experience regarding the keyboard's automatic, repetitious functions. ${ }^{28}$ The computer has a functional surplus compared to earlier writing technologies, and one needs to know how to avoid instigating an unwanted surplus function. This point is probably banal to most people who work with computers, but we wish to claim that it is basic knowledge, which has become banal through practically accomplished competencies. ${ }^{29}$ It is thus hard work to make the computer deliver the promised improvement in access and transparency.

Point three in the recipe is demanding in a different way, and it is quite revealing with regard to the new collective dimension of writing that goes into the incorporation of the EMM. The doctor is told that she is to "key in the whole name of the drug or part of it (e.g., diu or diural)." What does this request mean? That the doctor, after having completed the first two points, has now reached an interface, where she must "select" the prescribed drug for the patient. To select the right drug presupposes that she

fied Shole's layout by moving the letter " $r$ " to the same row as the other letters in "qwerty," which made it possible for the company's salesmen to impress potential customers by writing the word "typewriter" using just one row on the keyboard; Remington was evidently more successful than its competitors in stabilizing idea and product.

28. See, for instance, Deborah Lupton, "The Embodied Computer/User," in Cyber Space, Cyber Bodies, Cyber Punk: Cultures of Technological Embodiment, ed. Mike Featherstone and Roger Burrows (London: Sage, 1995), pp. 97-112; N. Katherine Hayles, "The Condition of Virtuality," in Masten et al., Language Machine (above, n. 22), pp. 183-206. In both texts, there are reflections on the material and embodied qualities of using computers for writing.

29. Hubert and Stuart Dreyfus argued convincingly in Mind over Machine (Oxford: Blackwell, 1986) that we become competent in a skill through a number of steps, starting with the detached, rule-dependent beginner and ending with the completely absorbed expert, acting intuitively on situated inputs. 
writes the name in the central open-text field (it is assumed that she knows she is supposed to write here). If the doctor writes only "diu" in the field, it will bring up all products beginning with these letters from a database-which may be helpful if she cannot remember the whole name "diural," or if she wishes to make the medication process easier for herself, or if she does not know the right spelling of the name; in any case, a new support of the doctor's hand and memory has appeared. One doctor told us that often, when she looked up a drug reported by the patient himself, the search was enhanced by keying in only part of the name of the drug: patients sometimes misspell such names, she explained. These comments hint at the located emergence of a new and creative writing-reading practice.

The next step is to "Press Enter." This requires some previous experience, because there is no key on the keyboard with "enter" on it ${ }^{30}$ All the same, the instruction looks so compelling that one has to assume the existence of the key. The computer-literate doctor knows well that "Enter" also means "return" or "new line"; there is, of course, no such key either, but experience, reasoning, or asking will guide the finger to the key with the broken arrow to the right on the keyboard. The already established experiences of the participants help the incorporation to pass what we like to call a weak semiotic transition in the interchange between recipe and keyboard. The participants empower, so to speak, the material-semiotic knots in the new medication practice. In the next section on printing it is pointed out that not everyone was armed with keyboard literacy from day one. It will also be evident how situated management compensated for such shortcomings in an impeccable balance between materiality and text.

The collective writing process is seen in still another way. Besides the electronic assistance in spelling and finding the relevant product, more social agents are now involved in deciding what counts as a relevant product. For instance, when the doctor writes "Cipramil," an antidepressive, and presses "Enter," a number of suggestions as to what can be prescribed will appear on the screen as a pull-down menu, showing the options the doctor must consider in order to prescribe Cipramil to a patient. We found that most doctors gladly accepted the offer of computer assistance, in spite of not knowing where the list of medicines on

30. We are aware that many keyboard designs do have the word "Enter" (and "Tab") written on one of the keys, but several others do not (including all Macintosh keyboards, it seems). Designers and decision makers might do well to avoid taking this explicit wording for granted when they create manuals for particular work-sites. 
the menu came from, other than the computer itself. Long after the introduction of the medicine prescription module, a consulting surgeon told us of the origin and dynamics of the list: it is updated twice monthly, based on the medicine catalogue published by the National Board of Health—but the doctors we spoke with did not know this piece of background history. Instead of acting as social mediators to underpin some original power springing from the National Board of Health, the doctors translated the list in accordance with their needs and requirements. Their efforts to put the new system into practice gave rise to new configurations in the understanding of medicine. The new, medicine-defined assemblage, consisting of various actors-among others, doctors who entered and selected medicines, a universal computer system with surplus functions, a graphic interface, and a list of medical products from the National Board of Health-now lays down limits for medicine, which do not correspond to previous experience on the ward or elsewhere.

A member of the prescription group put a piece of paper on the wall in the ward office with the heading "Errors in the manual-medicine." It was an invitation for everyone to write down their questions or criticism regarding the EMM, and the prescription group would then take the commentary into consideration in one of their meetings. For instance, a doctor wrote: "Insulin Mixtard is not included in the medicine database"; this expressed a conflict between personal experience and the textuality offered, raising doubt as to the adequacy of the database. ${ }^{31}$

In a similar vein, on several occasions doctors on the ward attempted to prescribe children's vitamins, "Multitabs Junior." This product was already incorporated into the contents of the medicine closet in the medicine room, and was routinely used by the staff, but whether the doctors entered the complete name of the product in the EMM, or just a part of it, no menu popped up with dosage options. This was indeed a test of the new medicating collective in action. The interesting thing is that doctors gave up trying to enter children's vitamins in the EMM; they were able to prescribe them orally, but not within the condensed materiality of the writing phase. Although almost everyone on the ward agreed that children's vitamins are medicine, a nonhuman actor,

31. Based on our findings, we think it likely that the consulting surgeon asked the rest of the prescription group not to take action based on this comment, because he knew about the source of the list: due to this knowledge, he would not be alarmed about the apparent mismatch between list and experience, and would prefer to deal with this type of disharmony in a low-key manner. 
a database, disagreed with that evaluation and therefore refused to allow "Multitabs junior" to be prescribed. The professional health workers on the ward had, in other words, acquired a new, strong member.

It can be seen in step 5 that the instructions are presumed to be followed sequentially - that is, the doctor carries out a point in the instructions, observes what takes place on the screen, perhaps enters a name or value, and moves on to the next step. Thus, at this point she is to carry out the order "Select the desired drug in the desired strength." This means that she must choose one of the suggestions regarding product and dosage for the patient, although the available assortment may well conflict with the doctor's own experience with the "right" products. Furthermore, the doctor must know what "select" means when choosing a product; here, too, one must assume considerable familiarity with computer-jargon and keyboard functions.

The next step is to press "Enter" again. In effect, the doctor has now acknowledged the new, nonhuman actor involved in prescription work, because it is the result of their joint efforts that now appears on the screen. Figure 2 is a graphic approximation of the active part of the screen image that appears when the doctor has chosen, for example, Cipramil as $10 \mathrm{mg}$ pills.

It soon became obvious during the fall of 2000 that the computer skills of the doctors determined their individual loyalty to the instructions. Some, for instance, preferred to use F-keys, while others preferred the mouse. Some felt tied to the "Tab" function in accordance with the instructions, while others moved through the available fields with the help of the mouse, according to their own priorities. Here we will refer only to the instructions, for, as a member of the prescription group said when we mentioned the rebellious doctors' unholy alliance with the mouse: "But they have to use the manual instead of following their intuition, or it isn't effective!" It is easy to see the dynamic shifts in the material-semiotic relations between formalism and terrain. ${ }^{32}$ And it is not crystal clear at this point what mode is the most effective. An intern stated that "it is stupid that we have to remember F2 and all the other codes. It would be better if one could see on the screen what to do."

It is extremely difficult to ensure a loyal transmission, even when it is between a locally situated formalism like the EMM and

32. This is also one of the main arguments and guiding principles in Berg, Rationalizing Medical Practice (above, n. 2). 
Product

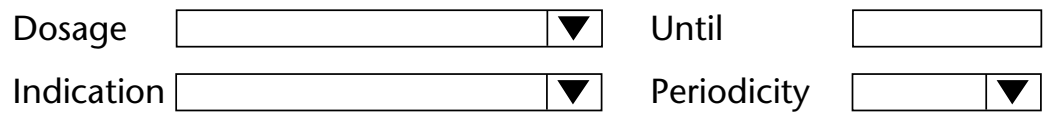

Figure 2. The active part of the computer screen where the doctor has to fill in a number of fields-alone, or assisted by various agencies.

a local terrain. We have already seen a glimpse of how the computer formalisms are sunk into the process of not only placing themselves but also being put into place in the situated practices in the ward, all of which testify to the transformative dimensions of incorporation. Loyalty is dynamic and many-sided in a heterogeneous, working relationship-a point that is further revealed in the review of the next steps in the instructions.

The text fields "Dosage" and "Indication" are hybrid fields of both free and predefined text. The pull-down Dosage menu will offer a number of choices for when the patient is to be given his medicine, and how much he is to have; it might, for instance, show " $1+1+0+0$," which in our example means that the patient is to have a $10 \mathrm{mg}$ Cipramil pill in the morning and at noon, but not in the evening or at night. The doctor can make this choice, and at the same time can add the comment "and as required." We see in step 7 of the instructions that the doctor and (as we now know) the computer must "enter the desired dosage," and in the finest collective manner, the computer's text can be mixed with the doctor's addition-for example, " $1+1+1+0$ and as required." It is, of course, a prerequisite that the doctor knows that this is a free-text field to write in; some did not realize this in the beginning, and they contented themselves with choosing among the computer's suggested wording. One doctor even said of the dosage field: "We are lazy, so we choose what is already written instead of writing something ourselves." Several others laid claim to a more active addition, though.

After pressing "Tab" in step 8-another key not found on the keyboard-the cursor moves, and with it the space for writing, to the "Until" field. While this field can be seen on the screen, it is not referred to in the instructions (which, as we learned, was a simple oversight)—but the doctors did not necessarily discover this insufficiency of the manual. "Until" was seen to comprise another kind of reconfiguration of the handling of medicine. Previously, doctors would note in the journal how many days the 
patient was to be given the product in question-for example, "6 days." The time period could always be altered. But now they must instead determine when the patient is no longer to receive the product. Several doctors found this a slightly odd conception of medication, but it gave them no hard problems after a brief pause for thought at the computer. Some told us that they did not feel bound by this formalism, for they would always be willing to change the final date, or they would expect the patient's own doctor to adjust the period, based on the patient's condition. Basically, they would not stop evaluating whether the patient was to continue with a product or not. The formalism's demand for an "until" date was translated into a doable work language without much ado. ${ }^{33}$ In the "Medicare manual" prepared by the producer of Medicare, it can be seen that the field "Until" is to be completed only in cases of "periodic ordination"; this limitation, however, was not pointed out to the doctors on the ward, but that did not stop their interacting with the "Until" field. The meaning of "periodic" in itself was a theme that only gradually found a stable level.

Another depression of the virtual "Tab" key leads to step 9, where the existence of the new writing collective is now made official: it says "Choose/write the desired indication"! Writing is as much a matter of pointing and clicking as pressing and spelling. The "indication" states the reason for the prescription; for example, the pull-down menu might offer a choice between "for pain" or "for severe pain." The doctor can choose one of these standard texts and/or write her own words in the field.

Yet another depression of the "Tab" key leads to step 11, "Choose periodicity." As already suggested, this phase in the recipe caused some confusion, until a consensus on the meaning and use of the "Periodicity" field gradually spread. The pull-down menu contains three suggestions for terms: "fixed, periodic, p.n." P.n. medicine is "per necessita" - that is, as necessary-and was quite clearly understood. To begin with, however, the doctors argued among themselves and with the nurses about what "periodic" medicine is, compared to "fixed" medicine. At one point they decided that periodic medicine is the medicine the patient begins to receive while hospitalized, in contrast to "fixed" medicine, which was designated as the medicine he is already receiving. This is an example of how the formalism and local actions gradually fuse in a pragmatic translation of an "original" intention. 
The final step, 12, says laconically "Press F8 = Save." And here one should be aware that "save" is used in its sense of "keep, store," not "rescue." Each product is to be prescribed separatelythat is, the doctor must choose to save the collective text each time she has filled out the prescription fields, and with this she exits the prescription module. Several doctors found this being forced away from the assigned workspace rather awkward, for they wanted to stay and finish the job of prescribing medicine, but they quickly learned to go back to the prescription module to finish this work activity in accordance with the gradually doable instructions.

In the material-semiotic density of the ward's sociotechnical practices, when the products in question have been entered into the EMM, we may now look at the next phase of the incorporation-namely, the printing of the medicine list.

\section{Printing Prescriptions}

When the nurse who is responsible for a specific patient is informed that the doctor has entered a prescription, she will make a printout copy of the "Medicine list-current." In other words, the nurses' part of the work of writing is to print. How is this done? To begin with, as we have learned already, we should follow the instructions for printing (Fig. 3).

Here, printing is clearly very different from the writing performed with a pen on paper. We see again that considerable knowledge is presumed, even though the instructions look very economical, with only two lines having more than two words, both containing wording that is recognizable from the world of health. The nurses must know what it means to "mark" something in order to carry out step 1 . And of course they must also know what "medicine list" means in this context-for there is no medicine list to mark, but rather an item on a menu that will lead them to a screen picture that can become a medicine list. At this point we could of course engage in a philosophical discussion about the logical conditions for the existence of medicine lists, but it would be irrelevant. It is rather a question of using the arrow keys to move the cursor down a menu to an item called "medicine list," and then selecting it, which can be done as soon as the cursor is placed on the word. The computer-literate health professional will know that this is the time for a (left-)click on the mouse, an operation that has to be learned by the novice.

When the writing/choosing operation has been carried out and the list has been marked, the nurse must go on to step 2: 


\section{Printing a medicine list}

1. Mark the medicine list

2. Press F3

3. Press Tab

4. Press F1

5. Mark "Print medicine list—current"

6. Enter

7. Press OK

Figure 3. The instructions for printing out the "Medicine list-current."

"Press F3." This is a laconic order, so there is not much else to do but obey-with all the reservations we have already touched on with regard to user-tactile experience with the computer keyboard.

Next comes the command "Press Tab." Several of the nurses on the ward did not know what "Tab" means, not even that it is a key on a keyboard. As we have already concluded, this is a quite reasonable lack of information. The "Enter" key, as was soon found out, caused a similar effect. When the nurses in the prescription group realized that they had presupposed more computer literacy in their colleagues than was justified, they took action in the dense field of practice between signs and materiality: a head nurse put "Dymotext" tape on the tabulator key and the line-shift key, thus translating them to "Tab" and "Enter," based on current needs and interests. Now, more actors in the practical world of the hospital ward could use them.

After having pressed F1 in step 4, the nurse reaches the most important item, and the one with the most obvious content of meaning: "Mark 'Print medicine list-current.'" Again, one should ignore philosophical puzzles about the reality of the current medicine list, and instead move on to step 6, "Enter," whose content has been considerably enhanced by the determined intervention of the head nurse. In spite of the support, the printing nurse must still be able to figure out that this is an order: in contrast to the previous items, there is no direct reference to action here. In this context it is likely that most people will automatically infer the word "press" in front of "enter," thus themselves creating the basis for carrying out the necessary order, so that they can go on to the final item in the instructions.

This is a reminder of one of the memorable passages in Ludwig 
Wittgenstein's Philosophical Investigations, where the builder communicates with his assistant by a "complete primitive language" that works by naming things-for example, "brick," "trowel," "slabs"-but without adding verbal requests like "give me." ${ }^{34}$ Their communication works due to a number of incorporated social rules, shared by the two, ensuring that the words of the bricklayer make sense to the helper and vice versa. Wittgenstein then introduced a famous concept to embed language and communication in social practice: "I shall also call the whole, consisting of language and the actions into which it is woven, the 'language-game.'"35 On the ward we often experienced such embedded language games. For instance, a nursing assistant passes the office where a nurse sits occupied with filling out some forms: "It was blank, the urine strip," the nursing assistant says through the doorway before walking on; "Well, the $\mathrm{pH}$ value was 6 , but I guess you don't care about that." "That's quite right," the nurse says, and continues to fill out her forms. It is the social arrangement that fills in the blanks.

Item 7 says only: "Press OK." Here, the nurse obviously must know that she is not to write the letters " $\mathrm{O}$ " and " $\mathrm{K}$ "; she is either to press the "Enter" key again, or to left-click on the mouse when the cursor on the screen lands on an OK-field. The word "OK" is a relatively recent cultural expression in Danish. According to Nudansk Ordbog (The Dictionary of Modern Danish), it has its roots in American usage. It may come from "all correct," where the letters " $\mathrm{o}$ " and " $\mathrm{k}$ " are are a humorous, incorrect usage of " $\mathrm{a}$ " and " $\mathrm{c}$ "; linguistic research is uncertain on the matter, however, and an alternative suggestion of roots in an African language has been made. Until a few years ago, we wrote "o.k." in Danish as an abbreviation for an unknown term; today, we leave out the two periods and use the abbreviation "OK" or "ok," meaning something along the lines of "all right," or "I see." In that sense, "OK" is a suitable conclusion to a set of abbreviated instructions of unknown origin. When a nurse presses "OK" she is saying "all right" to the simulacrum of the instructions, without having a clear idea of what it is that she ought to find all right-but she finds it out in reality.

It is important to state that these reflections on the striking attributes of language are not to be seen as a complaint about

34. Ludwig Wittgenstein, Philosophical Investigations (Oxford: Basil Blackwell, 1958), especially $\S 1-21$.

35. Ibid., p. 5. 
"poor instructions." Rather, they should be read as an encouragement for the technology student to increase the focus on the local, reflexive conditions for translating and being translated, regardless of the form an instruction takes. It is only in a diffusion model that a poor instruction can be replaced by a good one in accordance with "original" desires and plans. In the translation model, an "original" meaning is no longer decisive; on the contrary, local needs, desires, and expectations are decisive. An "OK" is a locally situated abbreviation of uncertain origin and dynamic consequences.

The inauguration of the nurses' use of the instructions followed this path in the best possible manner. The prescription group had arranged a number of group briefings on printing according to the instructions. The group of five nurses and nursing assistants whom we followed to a briefing experienced various unstable relations in their future writing-printing practice. Among other things, it was not clear whether both computers in the office were connected to the laser printer, and there was a lack of consensus as to how to start the printer. Both these aspects have significant consequences for the final OK of the instructions. Actually, the briefing in question ended indecisively when the group failed to print any result, and the participants were forced to return to their other, more familiar tasks on the evening shift. But one member of the prescription group continued and learned a little more about printing; she could then with greater assurance instruct her colleagues later. She became better at handling the new formalism locally, and the formalism became a more doable universal in situated health-care practices.

\section{Handling Medications}

Let us take a closer look at the most obvious result of the new writing-reading practice on the ward: the printed paper list with the doctor's prescriptions bearing the heading "Medicine listcurrent." On the surface of it, it is a piece of paper partly covered with black laser-printed text. If we look at it more closely, and begin to scratch the texture, it becomes clear that seeing the list as a material-semiotic system is more productive, because it reveals some of the tight connections between materiality and linguistic meaning. Here, we will point to a single dimension of the system with regard to the reconfigurations of doctors and nurses. ${ }^{36}$ The

36. We will touch on only a few points of this subject in this paper, but will make it the main theme of a forthcoming book on health-care informatics and STS. 


\section{Medicine List-Current}

Social security no $x x x x x x$

Name:

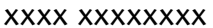

Prescribed Change/Disc. Form/Strength Name/Dosage

Fixed

\begin{tabular}{llll}
\hline $09-20-2000$ & $26-09-2000$ & Efervescent pills & Zantac \\
& $300 \mathrm{mg}$ & 1 pill at bedtime \\
\hline $09-20-2000$ & Injection liquid & Klexane \\
& $100 \mathrm{mg} / \mathrm{ml}$ & $20 \mathrm{mg}$ subcutaneous daily \\
\hline
\end{tabular}

Periodic

\begin{tabular}{lll}
\hline $10-02-2000$ & Pills & Diural \\
& $20 \mathrm{mg}$ & 1 pill daily \\
\hline
\end{tabular}

p.n.

\begin{tabular}{lll}
\hline $09-20-2000$ & Pills & Serepax \\
\hline $15 \mathrm{mg}$ & 1 pill twice daily \\
\hline
\end{tabular}

Figure 4. One of the very first medicine lists of the EMM to be used for measuring out medicine on the ward.

core of the new reconfigurations is to be found in (a) the creation of a stable column in the medicine list, and (b) the politics of daily rhythms.

In order to justify these odd bedfellows, it will be beneficial to look at an example of a "Medicine list-current," slightly modified to fit into this paper. It was created on day one of the EMM's introduction in the ward, and was printed for use on that same day. In other words, the list shows a still unsettled materialsemiotic system, trembling on the borderline between the banal and the foreign (Fig. 4). In the English translation of this particular list we have attempted to retain the heading, fonts, and font sizes, along with the horizontal lines, in order to give a fairly precise idea of what a list looks like when it is printed out to be used by a nurse for measuring out medicine. The reader should imagine that the list covers the top half of a standard (A-4) sheet of paper; at the bottom of the sheet is a line of text stating the date, the time, and the initials of the person who logged on to Medicare. ${ }^{37}$ 
At the time of production, the blanks in the prescription were filled in based on the doctor's entering data, on ideas of system designers and programmers with regard to adequate set-ups for data, and on the software's suitability for creating such fields. At this early stage of entering data into the EMM, the doctor primarily filled in the blanks based on her requirements and ideas of meaningful information as a medical doctor. For instance, is " 1 pill at bedtime" taken to be a clear, unambiguous message? It is a message that is communicated daily between health-care professionals in the verbal form preferred by most doctors as communication-but this conception of unambiguity does not take into consideration the column as a material tool for the nurses, to ensure greater precision in the task of measuring medicine at the correct time. One doctor stated directly to us that he found the $1+1+1+1$ code "idiotic and a nuisance." To him there was no connection between this notation and the daily rhythm of the individual patient. Most people take their medicine during their main meals - that is, three times a day; hence, the four times daily built into in the formalism do not fit: "You could say that the patient is forced to adjust to the hospital's rhythm, as defined by the four times," he stated. It is necessary to go into this subject more deeply in order to understand why the need by nurses, Medicare, and the computers for a new material-semiotic configuration very much depends on a shift in the doctors' writing practice.

Previously, it was the nurses themselves who filled out preprinted lists distinguished by grids, rows, and columns and designed for the tasks involved in measuring out medicine. But the prescription module is not (yet) designed for such tasks! ${ }^{38}$ When the nurse responsible for the patient in question has printed the medicine list, she puts it in a plastic folder at the front of the cardex made for the individual patient. The cardex is a thin, dark blue dossier containing various forms in a specified order, and placed along with the other patients' cardexes on a

vidual health professional on the ward rarely felt any need to log off Medicare after use. The local working collectives, especially those including nurses, had, in other words, no need to act out differentiated identities in regard to password formalism.

38. It is important to stress that, to us, the effective design process is not caused by "designers." Like "scientists" and "technologists," designers become "freestanding" agents with causal powers only as a result of delegation at the end of a number of heterogeneous social processes. The continued design of the EMM is evolving thanks to situated, microsocial processes of translation and transformation. See also Latour, Science in Action (above, n. 13), for more on this stance toward design and technology. 
shelf in the ward office. When the next normal time to administer medicine is approaching-that is, 8 a.m., 12 noon, 6 p.m., or 10 p.m. - the medicine list is recaptured from the cardex and taken along with the other medicine lists into the medicine room next door. Here it is laid beside the medicine closet. The nurse then begins to measure medicine into small plastic cups based on the information she extracts from reading the lists, one by one. We soon learned that the process of measuring out medicine was closely connected to the material-semiotic conditions of writing.

Thus, the nurse measures out the medicine by following a column with her eye (and perhaps a finger). But as can easily be seen in the example (Fig. 4), there are no printed columns or vertical lines to refer to in "Medicine list-current"! The table does fulfill its function in the light of medical and programming perspectives, but the professional group who most need the new list to prevent misreadings, the nurses, have lost the column's stabilizing effect on the eye's vertical movement, when compared with their preelectronic charts and forms. "Name/Dosage" is to show whether the patient should be given medicine at a given time (for example, in the evening). Even though the entry reads " 1 pill at bedtime," that is not in accordance with the concrete needs of the medicine room when the nurse measures out the products: does it mean "6 p.m.," "in the course of the evening," or "at bedtime"?

Previously, the text in the columns of the medicine list was well assimilated into the process of measuring out medicine, thus helping to maintain a high degree of certitude in this procedure. But the new "Medicine list-current" is not compatible with the former process, as we can see. The new situation is therefore awkward for the nurses. It is true that they no longer need to write down the medical products themselves, a task now left to the prescribing doctor and an electronic database system with a past. At the same time, however, a displacement in the balance between text and materiality has arisen in this crucial phase of the medicine's transformation from verbal prescription to physical consumption. The measurement phase was, so to speak, marked by a weak, vertical materiality, and something had to be done.

A new discipline arose fairly quickly around the writing of medicine prescriptions, where some of the nurses gradually took on the task of pushing the doctors to write correctly and on time-if not with enthusiasm, at least straightforwardly. A nurse expressed the sentiment: "We can't be bothered to be nursemaids for the doctors. They must remember to write the prescriptions 
themselves. Of course, they differ; some just write them, while others have to be reminded. It's probably a question of the generation gap, where we younger nurses refuse to do the doctors' remembering for them. . . . So it's a conflict that, on the one hand, we leave it to the doctors, and on the other hand, we are dependent on being able to print out the medicine list." This is a rather explicit expression of some of the articulation work that goes into making the formalism part of daily work.

In other words, a new kind of dependency has arisen in the complex, collective arrangements on the ward. The materialsemiotic and the sociotechnical dimensions clearly intersect. At the same time, the new situation illustrates the ambiguity of the work of interaction. Thus, the clearcut initial sharing of tasks in connection with the incorporation of the EMM is not simply transmitted to the relevant actors, as the diffusion model would have it; instead, the incorporation prompts a number of pragmatic transformations of roles, needs, and agencies. One of the senior interns did see herself as complying with the new demands-but in accordance with her own medical logic, as we soon realized. At one point she entered a prescription and wrote down the dosage as " $0+0+1$." She had no doubt, when we asked her, that the nurses would understand from the text that the patient is taking this medicine in the evening, but not in the morning or at midday; on the other hand, she did not find it necessary to write the fourth digit to tell that the patient is not taking the medicine at nighttime: "The nurses know that" she stated confidently. This is an example of a partial connection between some of the involved actors, where shared knowledge, daily rhythms, and ink-based columns on a sheet of paper are colliding in the attempt to make the new formalism work. ${ }^{39}$

In the local context, the medicine list must provide some kind of columns, which the nurses can use for measuring medicine. This can be illustrated by another medicine list, produced about a month later, and correctly completed-in the nurses' eyes (Fig. 5). We have added the vertical lines around the $6 \mathrm{p} . \mathrm{m}$. dosage to illustrate the nurses' requirements. Note that it is a question of training the eye and finger to check whether this patient is to have a specific product at this time. For instance, the patient is to have two 500-mg Panodil pills, but no Diural. If readings from the list are to be relatively stable, the doctors must learn to write according to the $1+1+1+1$ code, and not "four times daily." One 
Medicine List-Current

Social security no: $x x x x x x-x x$

Name: $\quad x x$

\begin{tabular}{|c|c|c|c|}
\hline Prescribed & Change/Disc. & Form/Strength & Name/Dosage \\
\hline \multicolumn{4}{|l|}{ Fixed } \\
\hline \multirow{2}{*}{$09-20-2000$} & & Pills & Panodil \\
\hline & & $500 \mathrm{mg}$ & $2+2+2-2$ \\
\hline \multirow[t]{2}{*}{$09-20-2000$} & & Pills & Diural \\
\hline & & $20 \mathrm{mg}$ & $1+0+0+0$ \\
\hline \multirow[t]{2}{*}{$10-02-2000$} & & Pills & Persantin \\
\hline & & $100 \mathrm{mg}$ & $2+0+2+0$ \\
\hline
\end{tabular}

Figure 5. A medicine list in harmony with the situated needs of the nurses.

can call it a compromise, where the nurses will somehow add vertical lines if only doctors, the computers, and the printer will live up to a disciplined writing practice where morning, noon, evening, and night are translated into numerical values.

The material-semiotic transformations developed further according to the needs arising in the course of the fall. Even though it was banned, several nurses began writing on concrete medicine lists because they need to write as part of their medicine-related practice. It appeared that, for some, the writing acted as a marker signaling uncertainty as to the correctness of the medicine list. In the sociotechnical arrangement of the EMM there had been no allowance made for this alliance with paper as a mnemotechnical tool. The reconfigured writing practice was expressed in various ways, from penciled question marks by the name of a product, to corrections in the dosage text, to penciled vertical lines, to crossing out of discontinued medicine. Often the nurses reflected on medicine in concrete work situations. ${ }^{40}$ For instance, a nurse looked at an item in a medicine list that stated that a patient was to be given morphine for severe pain. She knew from experience that morphine often causes patients to be constipated, and consequently this patient might well need something for that condition; she therefore chose to write down

40. Schon has made this argument in Educating the Reflective Practitioner (above, n. 20), and Suchman's critique of rationalist design ideals in Plans and Situated Actions (above, n. 7) is similar in many ways. 
her thoughts on the medicine list, to discuss the issue with others later.

"Medicine list—current" contains a column headed "Change/ Disc." It is intended to show when a product may have changed dosage or been discontinued-that is, treatment has been either completed or interrupted for a period. Some nurses mentioned the discrepancy between the title's claim to be a "current" medicine list and the reference to products not currently being given. A nurse described how she had measured out medicine for a patient who, from his bed, told her that according to the doctor he was no longer to have this product. She had not noticed the discrepancy during the measuring in the medicine room, where her eyes were fixed on the Name/Dosage column. Again, we see that an ideal simplification demands a good deal of work by the actors involved, in this case even a patient. The nurse further stated that she had begun crossing out the discontinued medicine with a pencil before going to the medicine room, so as not to measure it out by mistake. Another nurse showed us a list she had written on because she was not sure of the dosage shown for a certain product: her eyes had stopped at a surprising dosage in the text, making it necessary for her to put words on paper. That way she materialized her uncertainty, so that it was not forgotten, but could be followed up by herself or other nurses. One begins to see the dawning need to reclaim the materiality of the medicine list. The rule against writing is in effect capable of counteracting the aimed-for simplicity in handling medicine, so it must be betrayed with a layer of graphite added by hand to the machineprinted layer of ink.

Our last example illustrates well the often sublime transition between the material and semiotic dimensions of medicine. It proved impossible to prescribe children's vitamins through the EMM, because the product was not found in the module's database. In consultation with a doctor, a nurse therefore wrote "Multitabs Junior $1+0+0+0$ " with a ballpoint pen at the bottom of a "Medicine list—current," so that her child patient could be given the necessary vitamins; when the patient's other medicine was altered and new medicine lists printed, the handwritten prescription was cut off the original medicine list, put in a plastic pocket, and laid with subsequent lists. This mix of text and paper was in no way planned, but was shown to be both necessary and practical as a local counterprogram to the formal program of the medicine prescription module, which did not satisfy situated needs and interests. 
The incorporation of the medicine list arose from rules that were intended to ensure a simpler, more reliable procedure, but it meant that the nurses lost a writing tool that was significant for their collective work form. In other words, for the first couple of months after October 2, 2000, the EMM was exclusively seen as a set of rules, and not as a tool for the nurses and other health professionals. ${ }^{41}$ This pair of concepts expresses quite well what was put at risk on the ward. There was a continual transformation of the rules laid down, to accommodate the gradually recognized needs by (transformed) nurses for tools with which to make note of their deliberations. Halfway through the planned period of incorporating the module, the prescription group allowed the nurses to write on the "Medicine list-current" (but only in the right margin!). With this, both map and landscape, module and medicine handling were significantly altered in ways that were not planned before the inauguration of the system. For a time, at least, the EMM had become a stable actor in the hypercomplex, sociotechnical arrangements on the ward. ${ }^{42}$

\section{Conclusion}

We feel that it is both legitimate and productive to maintain the overall claim stated in the introduction that it is complicated to simplify a sociotechnical practice. Formalisms and processes involved in a hospital ward will be reconfigured in multiple ways before a new stability will arise around the simplified procedure-for example, the EMM-so that it appears as an improvement on the daily work routines. Stability is a result of dynamic processes, and the active loyalty of the actors involved is decisive in determining how long the new simplification remains stable. In the situated writings, readings, and handlings of the medicine

41. This play with words has been made in Yrjö Engeström, Learning, Working and Imagining: Twelve Studies in Activity Theory (Helsinki: Orienta-Konsultit Oy, 1990), pp. 171ff.

42. About a year after its introduction, we learned that the EMM was fulfilling its role less well. The consulting surgeon had left the ward, so the doctors were not being encouraged by an eager colleague to fulfill their roles in the local incorporation of the system. Several nurses had begun to write too extensively on the Medicine list-current, "so we will probably need to do something to straighten up the discipline on the use of the list," as a member of the group said. On the other hand, one day the printer suddenly started to pour out medicine lists for hanging on the wall-fitted with proper vertical lines; the prescription group had long ago asked for these lines to be part of the program, but the communication between the ward and the software company was intricate due to monetary and collaboratory gray-zones. In any case, the situated sociotechnical practices are clearly dynamic, and new stabilities will (have to) replace older ones. 
list, as we have suggested above, simplification is therefore an effect of a long series of transformations and shifts in previous procedures and activities, together with necessary translations of the new procedure.

The first of our two objectives in this paper was to show the benefits of employing a culturally grounded approach to studying the implementation of advanced technology in a community of interacting professional groups. The reading of the work manual for the EMM, with a focus on the shifts between banal and basic knowledge, teased out some of the situated nuts and bolts of the formalism. It showed that practitioners will act and react to formal requirements based on established work structures and preconceived ideas about the purpose and use of the formalism. In the multistable culture of health professionals there are only narrow spaces left for "new technology," which will thus be translated in order to fit in, or be doable-like the pragmatic use of the $1+1+1+1$ code by doctors, or the translation of the "Enter" key on the computer keyboard. In the process, the various actors were also molded or reconfigured-for example, to become the typing doctors, or the column-producing nurses-not as deliberate, rational choices, but rather as part of ongoing daily work. One should look out for such reconfigurations instead of taking deliberating, rational agencies for granted as such.

That leads to the second objective of this paper. We have attempted to show that it is insufficient to motivate the introduction of a new sociotechnical system by pointing to its successful use in other sociotechnical arrangements; nor is it adequate to assume that some intrinsic qualities of the system will guarantee a predictable outcome from its use. We suggest instead that the successful simplification of work processes may be seen as the effect of multiple undertakings, performed within a gradually expanded chain of situated, partially connected processes. Bruno Latour's concepts of diffusion and translation were put forward as ideal models to understand the dissemination of sociotechnical systems.

Related to our study of the implementation of the EMM, it makes sense to claim that a clearcut initial sharing of work tasks was not simply transmitted by social mediators to the relevant actors, as the diffusion model would have it. Instead, the implementation called for a number of pragmatic translation of roles, needs, and agencies. Things and people were being translated in various ways as the incorporation of the system took place, based on the actors' interests and needs. This is not to say that any 
translation goes; on the contrary, there will be many shared interests and wants. But what are shared interests, and what are not, can be known only when the formalism is activated in the work situation. Hence, it is not likely that abstract, built-in notions in an EMM about rationality, or the structure and organization of work, will determine the future medication practice in a given hospital ward: both practice and formalism will undergo transformations. Consequently, designers and decision makers need to learn about specific medical practices through empirical studies before new formal health-care systems are introduced to improve and rationalize professional practice.

Just as any computer system needs structure in order to work, it is obvious that clinical work is dependent on shared order and structuring principles-but located work practices are not driven just by rigid structures. If that were the case, the successful incorporation of the EMM on the ward would not have come about, since the professionals would have acted from within predetermined roles, and the material-semiotic work space would have been shattered. In the actual setting on the ward, the roles and tasks of nurses, doctors, secretaries, and others were combined and translated in a number of novel ways in order to meet the new formalism. Technology researchers, designers, and decision makers who wish to make medical work more rational and efficient need to pay direct attention to empirical, material-semiotic work settings where the formalism is going to be implemented. Situated readings of formal systems, and close attention to the constant, heterogeneous reconfigurations going on to stabilize activities in complicated professional practices, will thus contribute to improving our general understanding of sociotechnical work.

\section{Acknowledgments}

We wish to express our warmest thanks to the staff at Ward Z, Odense University Hospital for their openness, patience, and helpfulness during our field studies. Many thanks go also to Tine Kleif and Bibber Rasmussen, who read earlier versions of the Danish manuscript, pointing out a number of mistakes and inconsistencies; and to Patricia Lunddahl, who, at an early stage, translated a large part of the manuscript for the English version. The project was carried out with economic support from the Danish Research Agency's Freja Program. We also thank two anonymous referees for offering valuable suggestions for improvements. 